\title{
Os elos partidos e perdidos
}

Reginaldo Mattar Nasser

Muitas vezes encontramos o nosso destino por caminhos pelos quais enveredamos para o evitar.

(Jean de la Fontaine)

$\mathrm{E}$

M SEU novo livro Elos partidos, o professor Oliveiros Ferreira reafirma aquilo que tem sido uma constante em sua trajetória intelectual, um pensador das Ciências Humanas. De Marx a Durkheim, passando ainda por Gramsci, Lassale, Oliveira Vianna, Carl Schmitt e uma série de outros pensadores, das mais diversas correntes teóricas, Oliveiros discorre sobre cada um deles de maneira criativa e pouco ortodoxa, mas com o devido cuidado na utilização de seus conceitos, seja na história seja na política ou na sociologia. Mesmo quando afirma que seu objetivo é apreender os fatores reais de poder, o que, num primeiro momento, poderia nos dar a impressão de estar estritamente inserido no campo das ciências políticas, $\operatorname{logo}$ na seqüência de seu raciocínio estabelece as conexões entre a dimensão da política e as determinantes sociais, na tentativa de compreender as intricadas relações entre a sociedade civil e o Estado brasileiro, reencontrando assim com a sociologia.

Nessa obra se propõe a revisitar um dos temas que mais notabilizaram sua profícua carreira intelectual: compreender a marcante presença dos militares na história política brasileira. Seus propósitos são os mesmos de outras obras, compreender o processo político brasileiro que vai desaguar em 1964, a "longa noite hobbesiana" que se iniciou em 1821, quando as tropas do Exército no
Rio de Janeiro obrigaram o príncipe regente Pedro de Alcântara a substituir o ministro da Guerra, e se prolongou até o final do regime militar. Contudo, há algo de novo que é a busca incessante de um fio condutor que permita dar certa coerência ao processo histórico brasileiro em que as diferentes etapas "estão unidas por um elo que se traduz na conexão de sentido que pode ser estabelecida entre as ações dos diferentes personagens nos diversos momentos em que se examina a história" (p.3).

Oliveiros Ferreira aborda o passado com um olhar fixo no futuro, reexaminando os principais momentos de rupturas e crises políticas nas dimensões interna e externa do Estado em que se afloraram os graves problemas sociais e políticos da nação brasileira. Os descompassos, ou desencontros, entre as formas de organização do Estado e da Sociedade (Estado e Federação) durante toda a República só poderão ser devidamente compreendidos se atentarmos devidamente para "a transformação ou continuidade das instituições e a passagem de um sistema para outro".

Durante todo esse período analisado, destaca-se, no seu entender, a presença de três atores principais do enredo em que se desenvolvera o drama político brasileiro: o Estado (a União), os Estados da Federação (oligarquias) e os militares. Há que atentar para o fato de que, ao contrário dos militares, o Estado brasileiro dificilmente é reconhecido como protagonista da peça, é representado por outros personagens, especialmente a Força Armada que esteve sempre presente em 
praticamente todos os momentos de crise política. Aqui reside o verdadeiro drama, alerta Oliveiros, pois os espectadores tendem a confundir "as reais funções dos personagens e a Máscara que eles vestem para entrar em cena" (p.30).

De uma forma geral, a literatura especializada - poder-se-ia dizer os espectadores, na metáfora de Oliveiros Ferreira - entende que as transições democráticas na América Latina, e no Brasil em particular, tiveram como objetivo tácito ou explícito desmilitarizar a política. Tal empreitada - a democratização - era vista como mais, ou menos, eficiente à medida que conseguia manter os militares em seus quartéis, sem participação ativa na política brasileira. Nesse sentido, a democracia estaria consolidada no momento em que os civis estivessem exercendo um verdadeiro controle democrático sobre as ações dos militares, mantendo-os em suas funções primordiais, como a defesa das fronteiras do Estado.

Ora, de acordo com Oliveiros, há uma constante na história política brasileira que não podemos perder de vista, a fração vitoriosa das Forças Armadas - ou a totalidade delas - em todos os momentos de crise esteve sempre apoiada num setor civil. O problema é que os militares - retomando a linguagem do teatro - "não tinham como se mascarar; por isso, na brutalidade de seu papel, despertaram aplausos de parte da platéia, depois desconfiança, e finalmente a ira de praticamente todos os que lotam o grande palco nacional". Entretanto, conclui: estiveram sempre a serviço de um dos outros personagens (p.29). Assim a explicação do intervencionismo dos militares situar-se-ia menos no plano das intenções dos personagens, pretensamente imbuído de objetivos hegemônicos, e mais na dimensão da sociologia política. Para Oliveiros, não se trata de fazer uma teoria das intervenções militares, mas sim de compreender as razões que levaram à freqüente presença dos militares na política brasileira durante longo período. Pois, se o fizeram [os militares] é porque as instituições não se adequavam à realidade social nem correspondiam à idéia que os atores principais faziam do que devesse ser o país (p.52).

Nesse ponto, entendemos que sua interpretação do processo de crise do Estado brasileiro se insere na tradição do movimento político do Império conhecido como "regresso" que Oliveira Vianna, autor constantemente lembrado no livro, fazia questão de reverenciar. O senador do Império Bernardo P. Vasconcellos, líder do "regresso", entendia que "Os nossos males nascem de terem as reformas políticas precedido a reforma social" (Anais, sessão do dia 19.8.1841) -, em outras palavras, os transtornos causados por nossas instituições políticas resultariam, na maioria das vezes, do fato de não serem levadas em consideração as condições sociais e as particularidades históricas de nossa formação.

Pois bem, em 1965, com a edição do Ato Institucional n.2, o presidente Castelo Branco "quebrou o elo que unira os anéis que, ao longo da história republicana, simbolizavam a união dos setores civis a amplos setores militares", momento em que os políticos perderam suas posições de destaque no processo decisório em decorrência da extinção dos partidos e de sua influência na condução da política econômica. No dia 15 de novembro de 1889, destaca Oliveiros Ferreira, "a Força Armada foi ao poder, prenunciando 1964", e, muito embora tivessem propósitos diferentes, ambos 
destruíram a legalidade constitucional e criaram uma "legitimidade revolucionária” (p.60). Se a história, como nos diz Oliveiros, pode ser compreendida com um conjunto de "fatos que se ligam como os anéis de uma corrente, seja considerando o sentido da ação que os atores lhe emprestam no momento em que ocorrem e nos que se lhes seguem, seja pela inserção deles na evolução do quadro institucional do pais", podemos, após uma leitura atenta da obra, perceber também que um ou mais elos dessa corrente se perderam.

Em texto escrito no jornal $O$ Estado de S. Paulo (31.10.1966), Oliveiros Ferreira destacava os anos de transição da Monarquia para a República como um momento de crise de legitimidade em que o Exército "tornou o Estado responsável perante as Armas e se constituiu, na prática, na fonte real do Poder. Como, porém não era e não é o Estado, mas seu garante, criou uma grave contradição entre a legitimidade legal republicana...". Não custa nada lembrar o famoso discurso de Rui Barbosa no Senado (sessão de 3.11.1891) reconhecendo os tempos sombrios da República nascente:

enquanto D. Pedro II governou o Brasil nunca houve o menor estremecimento entre o Governo e a força militar. Sua Majestade soube alimentar sempre ao menos esta tranqüilidade nas fileiras militares, a observância automática dessa disciplina, que faz das organizações armadas a base da paz ambicionada pelos governos liberais e confundida por eles com a verdadeira segurança.

Estamos falando de legitimidade como um conjunto de princípios que atuam no interior das sociedades e que se traduzem num acordo com os cidadãos a aceitar a autoridade política. Como dizia o juris- ta e historiador Guglielmo Ferrero, esses princípios são como os "fios de seda que atam o dragão", e que, se rompidos, viveremos uma história de suspeitas e desencontros entre governantes e governados.

Ao final desse longo percurso, que se inicia no Império e termina na década de 1960, o leitor reconhecerá que há um recurso metodológico que perpassa toda a obra de Oliveiros Ferreira, a presença da história, não a história ex-machina pronta para realizar nosso destino político e social, mas aquela história que pode ser vista como um conjunto de experiências que foram testadas e vividas ao longo dos anos. Tal abordagem se explicita na obra quando Oliveiros fala, por exemplo, a respeito da idéia de Estado no Brasil, fazendo-nos ver os equívocos que cientistas políticos cometem ao tratar o Estado de forma inteiramente abstrata, como se fosse princípio imanente que se manifestaria alheio às circunstâncias históricas de cada país. O Estado "é uma unidade de associação dotada originariamente de poder de dominação e formada por homens assentados em um território" (p.2); porém, alerta Oliveiros, é o "apoio na imaginação popular que permite a essa associação fazer a guerra em nome da Nação" (p.3).

Para Oliveiros, "são os pequenos fatos, que permitem apanhar num relance o sentido dos processos históricos" (p.34l). Um de seus pensadores favoritos, Miguel Unamuno, observava que deveríamos olhar atentamente não apenas para os momentos grandiosos das revoluções e dos golpes de Estado, mas também para certos fatos ocultos, imperceptíveis, que, embora diluídos na trama intrincada do dia-a-dia da política, tornaram-se decisivos para profundas mudanças da mentalidade. 


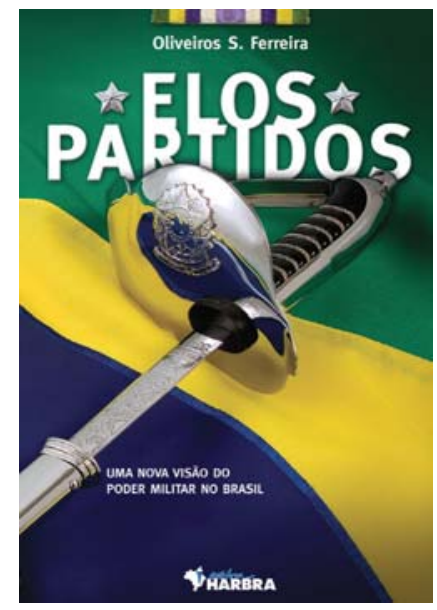

FERREIRA, Oliveiros S. Elos partidos: uma nova visão do poder militar no Brasil. São Paulo: Harbra, 2007. 594p.

Após a leitura desse livro, poderemos concluir que a verdadeira questão para Oliveiros é que, de uma forma ou de outra, falta ao Estado brasileiro autoridade para fazer frente às forças de desagregação social; sente-se cada vez mais a ausência de uma "comunidade de propósitos que faz com que os grupos sociais convivam não por estar juntos, mas sim por fazer algo juntos" (expressão de Ortega y Gasset em España invertebrada, Alianza Editorial, 2000). Ao trazer à cena uma série de personagens nas mais diversas situações, com as mais diferentes finalidades, se utilizando dos mais diversos meios, Oliveiros nos estimula não apenas a pensar a nossa história, mas nos provoca a assumirmos a responsabilidade sobre o nosso destino. Talvez esse seja mais um elo que se partiu e se perdeu no passado. Mas esse é um outro tema que, espero, o professor Oliveiros Ferreira possa abordar numa nova obra.

Reginaldo Mattar Nasser é doutor em Ciências Sociais pela PUC-SP, coordenador do curso de Relações Internacionais (PUC-SP). @-regmatar@uol.com.br 